\title{
LA-4775-MS
}

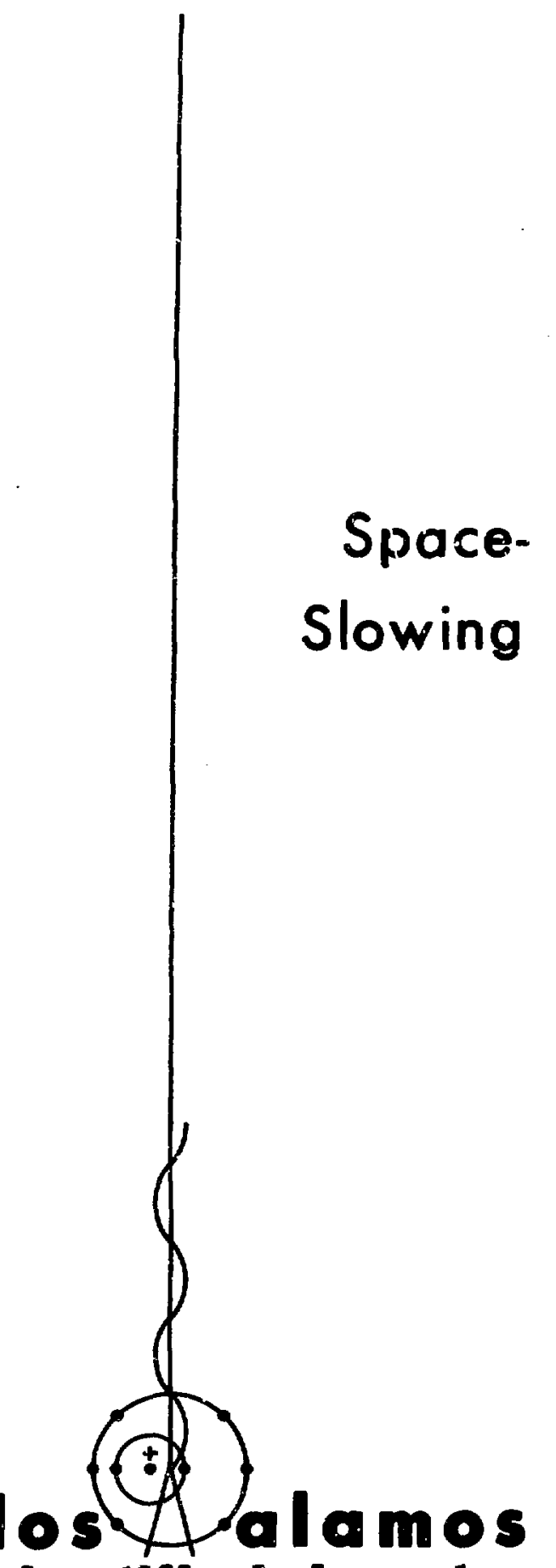

solontific iaboratory

of the University of California

LOS ALAMOS, NEW MEXICO 87544

$\downarrow$ 
This report was prepared as an account of work sponsored by the United States Government. Neither the United States nor the United States Atomic Energy Commission. nor any of their employees, nor any of their contractors, subcontractors, or their amployees, makes any warranty, express or implied, or assumes any legal liability or responsibility for the accuracy, completeness or usefuiness of any information, apparatus, product or process disclosed, or represents that its use would noi infringe privately owned rights.

This report, like other spe:ial-purpose documents in the LA. . .MS series, has not been reviewed or verified for accuracy in the interest of prompt distribution.

Printed in the United States of America. Availabie from National Technical Information Service

U. S. Department of Commerce 5285 Port Royal Road Springfield, Virginia 22151

Price: Printed Copy \$3.00; Microfiche \$0.95 
UC-15

ISSUED: January 1972

\section{Space- and Time-Dependent Slowing Down in Heavy Media}

by

C. R. Weisbin

R. A. Forster

D. B. Smith

N. Corngold *

NOTICE

This report was prepared as an account of work sponeored by the United Stater Government. Nefther the United States nor the United States Alomic Energy Commbation, nor any of thetr employers, not any of their contractors, subcontractors, of their employees, makes any warraniy, express or inplied, or amumed any loed linbility or sesponsibiltty for the accuracy, completenese or uscfulnese of any information, apparatus, product or proseas diecloced, or represents that its use product or proces disclosed, or represents
would not infringe privately owned rights.

"Los Alamos Scientific Laboratory Consultant. Presert address, California Institute of Technology, Pasedena, CA 91109. 
SPACE- AND TIME-DEPENDENT SLOWING DOWN IN HFAVY MEDIA

by

C. R. Weisbin

R. A. Forster

D. B. Smith

and

N. Corngold

\begin{abstract}
AUSTRACT
To evaluate the potential of the lead slowing-down-time spectrometex quantitatively as a nuclear safeguards assay device, the time-, space-, and energy-dependent neutron diffusion equation has been solved for heavy moderators, and a FJRTKAN-IV program, SLAHM (Slowing-Down Analysis in heavy Moderators), was written to perform the required integrations.

Using this new calculational tool, spectral and spatial distributions have been obtained at a variety of times following introduction of a 14$\mathrm{MeV}$ point source of neutrons into geveral different-sized lead assemblies. One cin apparently achleve a ${ }^{235} \mathrm{U} /{ }^{239} \mathrm{Pu}$ discrimination ratio $\geq 5$ with only limited gelf-shielding (even for $h: \mathrm{gh}$ enrichment fuels) by examining the energy regions from 2.8 to 3.8 and 50 to $100 \mathrm{eV}$ or, for highly enriched plutanium breeder fuel, 2.8 to 3.8 and 56 to $66 \mathrm{eV}$. Note that this technique requires a 2-m cube. Further, the neutron population for energies below the inelastic threshold based upon exponenilal attenuation $\left(e^{-B^{2}} \tau\right)$ involving the neutron age $\left(\tau \mathrm{cm}^{2}\right)$ must be estimated very carefully. The "true" age has been shown to be sensitive to both cross-section variation and the "free ride" afforded by the $(n, 2 n)$ interaction.
\end{abstract}

\section{INTRODUCTION}

This report describes a solution to the full space-, time-, and energy-dependent neutron-dt.ffusion equation and the application of that solution to a study of the relevance of the lead slowingdown-time spectrometer ${ }^{\prime}$ to the United States' effort in the field of nuclear safeguards. The lead spectrometer requires a pulse of high-energy neutrons, typically $14 \mathrm{MeV}$, to be emitted near the center of a large cube of lead. After these neutrons undergo some rather complicated nonelastic processes in the initial slowing down phase, they gradually focus into an energy band that can be correlated analytically with the time elapsed since emission of the source puise. By relating the time-dependent response of an unknown sample to the similar response of standard reference materlals, one can determine the composition of the unlizown sample quantitatively. Previous experiments ${ }^{2-4}$ have pointed out the dirficulty in the discrimination of $:{ }^{39} \mathrm{Pu}$ from ${ }^{235} \mathrm{U}$, caused by resonance self-shielding at near-thermal energies. Proposals have therefore been made to apply the lead spectrometer at energles as high as the sub-MeV ${ }^{5}$ region to eliminate this protlem and to take advantage of the higher flux intensities. Careful consideration of the slowing down process is fundamental to the underatanding and interpretation of the time-dependent response. 
The prospect of calculating the neutronic propertles of such a device appesrs stralghtforward at first, because age theory should hold well in such a large, heavy, nonabsorbing medium and the 1nelestic processes all take place within a short time. In fact, age theory does reasonably well if one has an accurate age value; however, such values are not readily ayallable in the literature. Table I 11lustrates the sensitivity of the calculated neutron Intensity at $3.5 \mathrm{eV}$ rsing simple age theory by assuming several "effective" energles for the Initlation of the elastic slowing down process. One observes that the relative neutron intensity calculated by means of age theory for a 1.3-m-diam sphere 18 almost a factor of 20 higher if the nonelastic processes yleld an effective neutron source of 350keV energy as compared to $1 \mathrm{MeV}$. Th.ts senattivity 1s, of sourse, even more dramat1c for sma1ler asBemblies. From this example, It is clear that accurate computation of the neutron intensities requires careful consideration of the slowing down process. The neutron spectra and Intensicy below the 1nelest1c threshold depend strongly on the treatment of nonelastlc reactions which scatter neutrons to keV and lower energies.

TABLE I

SERISITIVITY OF NEUTRON AGE IN LEAD TO EFFECTIVE INITIAL ENERGY

\begin{tabular}{|c|c|c|c|}
\hline $\begin{array}{l}\text { Inftial } \\
\text { Energy } \\
\text { (YeV) } \\
\end{array}$ & $\begin{array}{l}\text { Age to } \\
100 \mathrm{eV}^{\mathrm{V}} \\
\left(\mathrm{cms}^{2}\right)^{2}\end{array}$ & $\begin{array}{l}\text { Age to } \\
3.5 \mathrm{eV} \\
\left(\mathrm{cm}^{2}\right)\end{array}$ & $\begin{array}{l}\text { Relative } \\
\text { Intensity } \\
\text { at } 3.5 \mathrm{eV}, \\
1.3-\mathrm{m} \text { Sphere }\end{array}$ \\
\hline 1.05 & 3593 & 4536 & 1.00 \\
\hline 0.95 & 3492 & 4421 & 1.31 \\
\hline 0.75 & 3250 & 4152 & 2.45 \\
\hline 0.55 & 2927 & 3807 & 5.49 \\
\hline 0.35 & 2433 & 3296 & 18.11 \\
\hline
\end{tabular}

Detalled time-dependent neutronics calculations for heavy moderating waterials also are not wideapread In the 11terature. Th1s 18 true for a number of reasons. Monte Carlo techniques are timeconsuming beiause of the many collisions required per history. Multigrouping techniques are generalIf difflcult because of the many groups required and the difficultiee in choosing an approprlate tine and energy watrix. Hence, previous calculatlons ${ }^{5-7}$ have generally used a few broad energy groups, spasial variation in the normal mode (or none at al1), and ather crude treatsent of elast1c ocattering.
The aseumptions in this newer treatment include transport by diffubion theory and an age-theory expansion of the flux. Elastic scattering is assumed Isotropic in the center-of-mass system, and cross sections are computed In a fine-group structure. Within these approximations, the solution to the differential equations is obtained in terms of integrals. The FORTRAN-IV program SLAHI (Slowing-Down Analysis in Heavy Moderators) was written to perform the required integrations. The region above the inelastlc threshold is represented by 10,000 groups (100 energy $\times 100$ time bins). The spatial flux is expanded in orthogonal functions in elther spher1cal, cylindrical, or rectangular geometry. Thus, the numerical solution is virtually independent of the number of space points of interest.

\section{MATHEMATICAL DERIVATION}

The Boltzmann equation describing neutron transport for nonfisslonable waterials can ve written as

$\nabla \cdot \underline{\underline{\Omega}}(\underline{\underline{r}}, \underline{\Omega}, E, t)+\frac{1}{v} \frac{\partial N}{\partial t}(\underline{\underline{r}}, \underline{\Omega}, \vec{E}, t)+\Sigma_{T}(\underline{\underline{r}}, \underline{\Omega}, E) N(\underline{\underline{r}}, \underline{\Omega}, E, t)$

$=\int S N\left(\underline{I}, \underline{\Omega}^{\prime}, E^{\prime}, t\right) \Sigma_{g}\left(\underline{I}, \underline{\Omega}^{\prime}+\underline{\Omega}, E^{\prime}+E\right) d E^{\prime} d \Omega^{\prime}+S(\underline{I}, \underline{\Omega}, E, t)$. $\nabla$

里

$\underline{\mathbf{r}}$

t

$n(\underline{r}, \Omega, E, t)$

$\mathbf{v}$

$N(\underline{r}, \boldsymbol{\Omega}, E, t)$

$\Sigma_{T}(\underline{x}, \underline{\Omega}, \mathrm{E})$

$\Sigma_{\Omega}\left(\underline{r}, \underline{\Omega}^{\prime} \rightarrow \underline{\Omega}, B^{\prime}+E\right)$ macroscoplc differentlal-acattering dian)

divergence vector $\left(\mathrm{cm}^{-1}\right)$ unit solld-angle vector (steradians) position of interest $(\mathrm{cm})$ time of Interest (sec) angular netrtion denstey: number of neutrons at position $I$ with energy $E$, going in direction $\Omega$ at time $t$ per unit volume, untt solld angle, and unit energy (neut:ons/ $\mathrm{cm}^{3}$ steradian - MeV) neutron speed (cm/sec) angular neutron flux = uv (neutrons/ $c m^{2}$ - stersdian - MeV - sec)

macroscopic total cross section at position $x$ for neutrons of energy E going in direction $\Omega\left(\mathrm{cm}^{-1}\right)$

\footnotetext{
cross section at position I for transferring neutrons with energy $B^{\prime}$ and direction $\Omega^{\prime}$ to energy $E$ and direction $\Omega$ per unit of final energy and solld angle (cm:-1/MeV - stera-
} 
$S(\underline{r}, \underline{\Omega}, E, t)$

external source of neutrons at position $\underline{r}$, energy $E$, direction $\underline{\Omega}$, and time $t$ per unit of volume, energ\%, direction, and time (neutron $/ \mathrm{cm}^{3}$ steradian - MeV - sec)

Ecuation (1) is integrated over all angles (d $\Omega$ ...) by assuming that the medium is isotroptc for all processes; the angular dependence of the differential-scattering cross section is only a function of the dot product $\left(\Omega^{\prime} \cdot \Omega\right)$.

$$
\begin{aligned}
\nabla \cdot J(\underline{r}, E, t)+\frac{1}{v} \frac{\partial \phi}{\partial t}(\underline{r}, E, t)+\Sigma_{T}(\underline{r}, E) \phi(\underline{r}, E, t) \\
\quad=\int_{E^{\prime}} \phi\left(\underline{r}, E^{\prime}, t\right) \Sigma_{s^{\prime}}\left(\underline{r}, E^{\prime}+E\right) d E^{\prime}+s(\underline{r}, E, t) .
\end{aligned}
$$

The new quantities that appear are defined as: $J(\underline{r}, E, t) \quad$ current vecior $=\int N(\underline{r}, \underline{\Omega}, E, t) \underline{\Omega} d \Omega$

$$
\text { (neutrons } / \mathrm{cm}^{2}-\mathrm{MeV} \text { - sec) }
$$

$\phi(\underline{r}, E, t) \quad$ scalar flux $=\int N(\underline{r}, \underline{\Omega}, E, t) d \Omega$

$$
\text { (neutrons } / \mathrm{cm}^{2}-\mathrm{MeV} \text { - sec) }
$$

$\Sigma_{s}\left(\underline{r}, E^{\prime} \rightarrow E\right)$ macroscopic differential-acattering cross section at space point $\underline{r}$ for scattering from $E^{\prime}$ to $E$ $=\int \Sigma_{g}\left(\underline{\mathbf{r}}, \mathrm{E}^{\prime}+\mathrm{E}, \underline{\Omega}^{\prime} \cdot \underline{\Omega}\right) \mathrm{d} \Omega \quad\left(\mathrm{cm}^{-1} / \mathrm{MeV}\right)$

$s(\underline{r}, E, t)$

$$
\text { external source }=\int S(\underline{\underline{r}}, \underline{\Omega}, E, t) \mathrm{d} \Omega
$$$$
\text { (neutrons } / \mathrm{cm}^{3}-\mathrm{MeV}-\mathrm{sec} \text { ) }
$$

\section{DIFPUSION-THEORY APPROXIMATION}

The removal term is divided into a sum of elasEfC and nonelastic components, and the scatering integral is represented explicitiy as the wum of contributiors from elast1c, discrete-inelast $1 c$, and continuum interactions. ${ }^{8}$ Diffusion theory is reasonable bectuse most of the neutrons are quickly (1ess than 1. Hsec) degraded to energles below which there 18 little absorption and thus are not expected to have migrated far from the source. Neutrons of these lower energles are essentlally diffusing elastically in a rother large system.

Converting the variable of Interest to neutron density per unit of velocity and applying Ficks' 1aw, one obtains the following form of the diffusion equation from Eq. (2)

$-\frac{v \nabla^{2} n(\underline{r}, v, t)}{3 \Sigma_{t r}(\underline{r}, v)}+\frac{\partial n}{\partial t}(\underline{r}, v, t)+v \Sigma_{n e}(\underline{r}, v) n(\underline{r}, v, t)$

$$
\begin{aligned}
= & \int v^{\prime} n\left(\underline{r}, v^{\prime}, t\right) \tau_{e 1}\left(\underline{r}, v^{\prime}+v\right) d v^{\prime}+S_{1}(\underline{r}, v, t) \\
& +S_{2}(\underline{r}, v, t)-v \Sigma_{e j}(\underline{r}, \underline{v}) n(\underline{r}, v, t)+s(\underline{r}, v, t) .
\end{aligned}
$$

The discrete inelastic and continuum integrals have been denoted by $S_{1}$ and $S_{2}$, respectively. other quantitles defined in Eq. (3) Include $n(\underline{r}, v, t)$ neutron density/velocity at time $t$ $\left(\mathrm{n} / \mathrm{cm}^{3}-\mathrm{cm} / \mathrm{sec}\right)$

$\Sigma_{t r}(\underline{r}, v)$ macroscoplc transport closs section ( $1 / 3 D$ where $D$ is the diffusion coeffient) $\left(\mathrm{cm}^{-1}\right)$

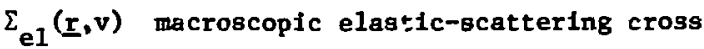
section $\left(\mathrm{cm}^{-1}\right)$

$\Sigma_{n e}(\underline{r}, v)$ macroscoplc nonelastic cross section $\left(\mathrm{cm}^{-1}\right)$

$s(\underline{r}, v, t)$ external source/velocity ( $\left.\mathrm{n} / \mathrm{cm}^{3}-\mathrm{cm} / \mathrm{sec}-\mathrm{Bec}\right)$

\section{AGE EXPANSION}

The facts that the moderator is a heavy materlal and that the flux spectrum is expected to approach $1 / E$ asymptotically suggest that ove expand $n\left(\underline{r}, v^{\prime}, t\right) v^{\prime 2}$ about $n(\underline{r}, v, t) v^{2}$ in a two-term Taylor serles to evaluate the scattering integral. If one now assumes that elastic scattering is 1sotropic in the center of mass and constant within the range of an elestlc integral, the first of the terms from the scattering integral just cancels the removal terti owing to elastic scattering, and one obta1ns

$$
\begin{aligned}
& -\frac{v \nabla^{2} n(\underline{r}, v, t)}{3 \Sigma_{t r}(\underline{r}, v)}+\frac{\partial n}{\partial t}(\underline{r}, v, t)+v \Sigma_{n e}(\underline{r}, v) n(\underline{r}, v, t) \\
& =\frac{\sum_{e 1}(\underline{r}, v)}{A} \frac{\partial}{\partial v}\left[n(\underline{\underline{v}}, v, t) v^{2}\right]+S_{1}(\underline{r}, v, t) \\
& +S_{2}(\underline{r}, v, t)+s(\underline{r}, v, t) .
\end{aligned}
$$

In $\mathrm{Eq}$. (4), the derivative term with reapect to $v$ Is multiplied by $1 / A$, a very small number. However, the mathematical form of the equation is very different if this term is not present.

\section{ORTHOGONAL FUNCTION EXPANSION}

The neutron density ia expanded into a set of orthogonal functions $f_{K}(r)$. (Recal1 thet $\underline{r}$ otands for $[x, y, z]$ or $[r, \theta, \phi]$, 


$$
n(\underline{r}, v, t)=\sum_{X} f_{R}(\underline{r}) n_{R}(v, t)
$$

where the $f_{\mathrm{R}}(x)$ are orthonormal solutions to the Helmholtz equation

$$
\nabla^{2} f_{K}(\underline{r})+B_{K}^{2} f_{R}(r)=0
$$

with the boundary condition $f_{k}\left(r_{g}\right)=0, r_{g}$ being a point on the surface and $\int f_{z}(\underline{x}) f_{L}(\underline{r}) d V=\delta_{K L}$.

The external source and discrete-1nelastic and continuum Integrals are simflarly expanded. This requires a homogeneous mediun within the boundary so that macroscopic cross sectlons can be taken as Independent of position. The external source 1s located at the center of the moderating assembly, with one neutron emitted lsotropically in the lab system at time $t_{0}$ with energy $E_{0}$. Implementing the above conditions, we have

$$
\begin{aligned}
s(\underline{r}, v, t) & =\sum_{K} f_{K}(\underline{r}) s_{K}(v, t) \\
S_{1}(\underline{r}, v, t) & =\sum_{K} f_{K}(\underline{r}) S_{1}^{K}(v, t) \\
S_{2}(\underline{r}, v, t) & =\sum_{K} f_{K}(\underline{r}) S_{2}^{K}(v, t) \\
B_{R}(v, t) & =\delta \frac{\delta\left(\underline{r}-r_{0}\right)}{4 \pi r^{2}} \delta\left(\nabla-v_{0}\right) \delta\left(t-t_{0}\right) f_{R}(\underline{r}) d v \\
& =\delta\left(v-v_{0}\right) \delta\left(t-t_{0}\right) f_{K}\left(r_{0}\right)
\end{aligned}
$$

\section{vI. BLASTIC SCATTERING ONLY}

Consider f1rst the energy region $E>E_{0}, \theta$ where $E_{0} 1_{8}$ the source energy and $\theta i_{8}$ the energy of the lowest exc1ted level. In this cese, the only scattering contribution 18 from elastic scattering, and one obtajns

$\frac{v}{3 \Sigma_{t r}(v)} n_{K}(v, t) B_{R}^{2}+\frac{\partial}{\partial t} n_{K}(v, t)+v \Sigma_{n e}(v) n_{K}(v, t)$

$=-\frac{\tau_{e-1}(v)}{1} \frac{\partial}{\partial v}\left[n_{K}(v, t) v^{2}\right]+\delta\left(v-v_{0}\right) \delta\left(t-t_{0}\right) f_{R}\left(r_{0}\right)$.

VII. METHOD OF SOLUTION

Equation (11) Is solved by taking laplace transform: of the time vartable, thus reducing Eq. (11) to a speed-dependent. Inear differential equation that can be solved directiy. This solution 18 then Invered to reconstruct the time dependence for each of the spatial harmonics. The final solution 18 obtalned by synthesizing each of the spatial modes according to $\mathrm{Eq}$. (5). Cross-section variation $18 \mathrm{sim}-$ ulated by a histogram (with many bins), and a boundary condition 18 applied numerically to account for discontinuities caused by the histogram simulation. Define the Laplace transform,

$$
\tilde{n}_{K}(v, \lambda)=\int_{0}^{\infty} d t e^{-\lambda t} n_{R}(v, t),
$$
and apply the operator $\int_{0}^{\infty} \mathrm{dt} \mathrm{e}^{-\lambda t} \ldots$ to $\mathrm{Eq} \cdot(11)$ to
obtain

$$
\begin{aligned}
\frac{\partial}{\partial v}\left[\tilde{n}_{\mathrm{K}}(v, \lambda) v^{2}\right] & -\frac{A}{\sum_{e 1}(v)}\left(\frac{B_{K}^{2}}{3 \Sigma_{t r}(v)}+\frac{\lambda}{v^{2}}+\frac{\sum_{n e}(v)}{v}\right) \\
& \times v^{2} \tilde{n}_{k}(v, \lambda)=0,
\end{aligned}
$$

for $t>t_{0}, v<v_{0}$. For a perticular energy interval, the group-averaged cross section may be taken as constant.

\section{BOUNDARY CONDITION}

For the highest energy group, the applicable boundary condition can be derived by going back to the transformed equation

$$
\begin{aligned}
& \frac{\Sigma_{e l}}{A} \frac{\partial}{\partial v}\left[\tilde{n}_{K}(v, \lambda) v^{2}\right]+\delta\left(v-v_{0}\right) e^{-\lambda t_{0 f_{K}}}\left(r_{0}\right) \\
& =\frac{v}{3 \Sigma_{t r}} \tilde{n}_{K}(v, \lambda) B_{K}^{2}+v \sum_{n} \tilde{n}_{K}(v, \lambda)+\lambda \tilde{n}_{K}(v, \lambda),
\end{aligned}
$$

and integrating from $v=v_{0}-\varepsilon$ to $v=v_{0}+\varepsilon$ where $\nabla_{0}$ is the highest speed in the problea and epsilon is Infinitesmally small. One finds

$$
\tilde{n}_{R}\left(v_{0}, \lambda\right)=\frac{A e^{-\lambda t_{0}} f_{R}\left(r_{0}\right)}{v_{0}^{2} \Sigma_{e 1}}
$$

For any other group, the boundary condition is obtained by integrating Eg. (14) from $v=v_{B}=\varepsilon \equiv v_{B}-$ to $v-v_{B}+\varepsilon \equiv v_{B}+$ where $v_{B}$ is the lower velocity 
bound of group $B$. In the 11 init as $\varepsilon$ approaches zero, tris reduces to

$$
\tilde{n}_{K}\left(v_{B^{-}}, \lambda\right)=\ddot{n}_{K}\left(v_{B^{+}}, \lambda\right) ;
$$

1.e., the neutron density at some energy boundery $B$ as determined irom the solutions in groups above and below the boundary (which may, of course, have dffferent cross sections) must be equal. For the top group, the solution to Eq. (14) is given by

$$
\begin{aligned}
& \tilde{n}_{K}(v, \lambda)=\frac{1}{v^{2}} \frac{f_{K}\left(r_{o}\right)_{A}}{\Sigma_{e l}} e^{\frac{\lambda_{A}}{\Sigma_{e 1}}\left(\frac{1}{v_{0}}-\frac{1}{v}-\frac{t_{o} \Sigma_{e 1}}{A}\right)}
\end{aligned}
$$

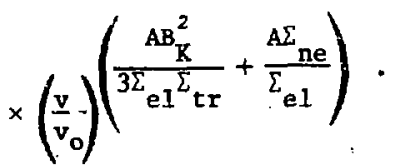

The form of the solution for lower-energy groups (at1li elastic scattering only) is simflar to Eq. (17) modified by a coeffictent $F_{K}(v)$ resulting irom application of $\mathrm{Eq}$. (16) at each preceding bcundary. $F_{K}(v)$ can be writien as

$$
F_{K}(v)=\prod_{\ell=1}^{j-1}\left(\frac{v_{\ell}}{v_{0}}\right)\left(c_{\ell}-c_{\ell+1}\right)
$$

where

$$
c_{\ell}=\frac{\mathrm{AB}_{\mathrm{K}}^{2}}{3 \Sigma_{\mathrm{el}}^{\ell} \Sigma_{\mathrm{tr}}^{\ell}}+\frac{\mathrm{A} \Sigma_{\mathrm{ne}}^{\ell}}{\Sigma_{\mathrm{el}}^{\ell}}
$$

$\Sigma_{e l}^{\ell}=$ macroscopic total elastic cross sestion of energy group $\ell$ bounded by speẹds $v_{\ell}$ and $v_{\ell \cdot 1}$.

$v_{\ell}=$ lower velocity boundary of group $\ell ; j$ is the group containing $v\left(v_{\ell}>v_{\ell+1}\right)$.

As expected, for the case of ccnstant cross section, $F_{K}(v)=1$ and boundary conditions do not affect the solution.

Furthermore, the time-dependent term in Eq.

(17) 1 s generallzed to

$\lambda A\left\{\left[\sum_{\ell=1}^{j-1} \frac{1}{\Sigma_{e l}^{l}}\left(\frac{1}{v_{\ell-1}}-\frac{1}{v_{\ell}}\right)\right]+\frac{1}{\Sigma_{e 1}^{j}}\left(\frac{1}{v_{j-1}}-\frac{1}{v}\right)-\frac{t_{0} \Sigma_{l 1}^{3}}{A}\right\}$, so that, In general, Eq. (27) becomes

$\tilde{n}_{K}(v, \lambda)=\frac{F_{K}(v) \tilde{I}_{K}\left(r_{o}\right) A}{v^{2}{ }_{e 1}^{j}}$

$\lambda \Lambda\left\{\left[\sum_{\ell=1}^{j-1} \frac{1}{\sum_{e 1}^{\ell}}\left(\frac{1}{v_{\ell-1}}-\frac{1}{v_{\ell}}\right)\right]+\frac{1}{\sum_{e l}^{j}}\left(\frac{1}{v_{j-1}}-\frac{1}{v}\right)-\frac{\sum_{o} \Sigma_{e l}^{i}}{A}\right\}$

$\times\left(\frac{v}{v_{0}}\right)\left(\frac{A B_{R}^{2}}{3 \Sigma_{E I}^{j} \Sigma_{t r}^{j}}+\frac{A \Sigma_{\text {nee }}^{j}}{\Sigma_{e l}^{j}}\right)$

\section{TIME TNVERSION}

One next inverts $\mathrm{Eq}$. (20) to regain the funccional dependence of the time vartable. Define

$$
M(v) \equiv A\left\{\left[\sum_{\ell=1}^{j-1} \frac{1}{\sum_{e 1}^{l}}\left(\frac{1}{v_{\ell}}-\frac{1}{v_{\ell-1}}\right)\right]+\frac{1}{\sum_{e 1}^{j}}\left(\frac{1}{v}-\frac{1}{v_{j-1}}\right)+\frac{\sum_{u_{e 1}^{2}}^{\Sigma^{2}}}{A}\right) .
$$

The time dependence of $\mathrm{Eq} .(20)$ is now contained golely in the term $e^{-\lambda M(v)}$. Recall that

$\int_{0}^{\infty} d t e^{-\lambda t} \delta(t-c)=e^{-\lambda c}$ if $c$ is a positive constant

$$
=0 \text { otherwise. }
$$

Then, for elastic scattering only

$\mathrm{B}_{K}(v, t)=\frac{F_{K}(v) f_{K}\left(r_{0}\right) A}{v^{2} \Sigma_{e 1}^{j}} \delta[t-M(v)]\left(\frac{v}{v_{o}}\right)\left(\frac{A B_{K}^{2}}{3 \Sigma_{e l}^{j} \Sigma_{t \tau}^{j}}+\frac{A \Sigma^{j}}{\Sigma_{e l}^{j}}\right)$,

and the solution to $\mathrm{Eq}$. (11), for elastic scattering only, can be written as

$n(\underline{r}, v, t)=\frac{A}{v^{*} \sum_{e l}^{j}} \delta[t-M(v)]$

$\times \sum_{\bar{R}} f_{K}(r) f_{K}\left(r_{o}\right) F_{K}(v)\left(\frac{v}{v_{0}}\right)\left(\frac{A B_{K}^{2}}{3 \Sigma_{e 1_{t r}^{j}}^{j}}+\frac{A \Sigma_{n e}^{j}}{\Sigma_{e I}^{j}}\right)$ 
$X$. EXTENSION TO INCLUDE DISCRETE INELASTIC AND $(n, 2 n)$ REACTIONS

The solutions for the energy regions below $E_{0}-\theta$, Including discrete inelastic and continuum contributions, are obtalned in an analogous fashion. The differential equation in speed is now, however, Inhomogeneous with respect to source terms containIng Inelastic and $(n, 2 n)$ reactions followed by elastic slowtriz down.

The final solution including all contributions Is given below. Level interactions have been assumed to take place with an Infinitely heavy target, and nonelastic reactions are assumed to occur instantaneously. This solution is obtained from the Inhomogeneous equation using the variation-or-parameters technique. The result is

$n(\underline{r}, v, t)=\frac{A}{v^{2} \Sigma_{e l}^{j}} \delta[t-M(v)] \sum_{K} f_{K}(\underline{r}) f_{K}\left(r_{0}\right) F_{K}(v)$

$\times\left(\frac{v}{v_{0}}\right)\left(\frac{A B_{K}^{2}}{3 \Sigma_{e 1}^{j} \Sigma_{t r}^{j}}+\frac{A \Sigma_{n e}^{j}}{\Sigma_{e 1}^{j}}\right)+\frac{A}{v^{2} \Sigma_{e l}^{j}} \sum_{K} f_{K}(\underline{r}) G_{K}(v)$

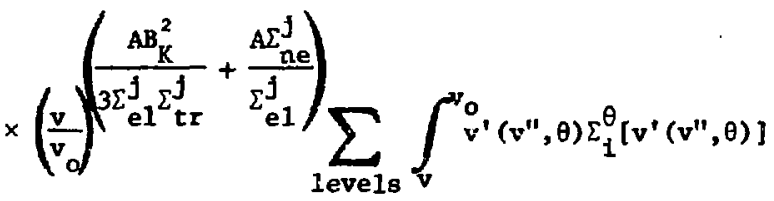

$\times n_{K^{\prime}}\left\{v^{\prime}\left(v^{\prime \prime}, \theta\right), t-\left[M(v)-M\left(v^{\prime \prime}\right)\right]\right\}\left(\frac{v_{o}}{v^{\prime \prime}}\right)\left(\frac{A B_{K}^{2}}{3 \Sigma_{e 1}^{j} \Sigma_{t r}^{j}}+\frac{A \Sigma_{n e}^{j}}{\Sigma_{e 1}^{j}}\right){ }_{d v^{\prime \prime}}$ $+-\frac{A}{v^{2} \Sigma_{e 1}^{j}} \sum_{K} f_{K}(\underline{\Sigma}) H_{K}(v)\left(\frac{v}{v_{0}}\right)\left(\frac{A B_{K}^{2}}{3 \Sigma_{e 1}^{j} \Sigma_{t r}^{j}}+\frac{A \Sigma_{n e}^{j}}{\Sigma_{e 1}^{j}}\right)$

$\times \int_{v_{2 n}}^{v_{0}} \int_{v}^{v^{\prime}}\left(\frac{v_{o}}{v^{\prime \prime}}\right)\left(\frac{A B_{R}^{2}}{3 \Sigma_{e 1}^{j} \Sigma_{t r}^{j}}+\frac{A \Sigma_{n e}^{j}}{\Sigma_{e 1}^{j}}\right)$

$$
\times n_{k}\left\{v^{\prime}, t-\left[M(v)-M\left(v^{\prime \prime}\right)\right]\right\} \Sigma_{2 n}\left(v^{\prime}+v^{\prime \prime}\right) d v^{\prime \prime} d v^{\prime},
$$

where $\Sigma_{1}^{0}\left[v^{\prime}\left(v^{\prime \prime}, \theta\right)\right]$ 1s the Inelastic cross section at speed $v^{\prime}$ for exciting level $\theta$, and the neutron emerges from the reaction with speed $v^{\prime \prime}$ and slows down elastically to speed v. $\Sigma_{2 a^{\prime}}\left(v^{\prime}+v^{\prime \prime}\right)$ is the macroscopic d1fferential $(n, 2 n)$ cross section at $v^{\prime}$ for scattering to $v^{\prime \prime}, G_{K}(v)$ and $H_{k}(v)$ are the terms resulting from application of the boundary condition, Eq. (16), and are rather complicated functions.

None of the three functions $F_{K}(v), G_{K}(v)$, or $H_{K}(v)$ 1s used explicitly in SLAFM. Instead, Eq. (16) is satisfied numerically at each velocity boundary $v_{B}$.

The three terms in Eq. (25) are easily interpreted. The first is simply those neutrons reaching $v$ directly from the source by elastic scatterIng only. The second term Includes those neutrons whose last nenelastic scattering collision (before reaching v) was a discrete Inelastlc scattering, and the third term comprises those neutrons whose last nonelastic transfer was by an $(n, 2 n)$ colliston. The $(n, 2 n)$ procesy scatters neutrons from $v^{\prime}$ to $v^{\prime \prime}$ where they begin to slow down elastically to $v$. Because both the inftial speed $v^{\prime}$ and the final speed $v^{\prime \prime}$ are variables, the double Integral results.

\section{NUMERICAL CONSIDERATIONS}

Equation (25) is solved, one group at a time, starting with the highest energy group and proceedIng stepwlse downward to the group that includes the lowest-1ylng level for lead ( $2570 \mathrm{ke}$ ). Each flux computed in this energy range is stored for later use as an effective source for computation of the flux at lower energles. Neutrons below $570 \mathrm{keV}$ can only slow down to energies of interest by means of elastic scattering for which an analytical expression is avallable. Therefore one can compute the neutron Intensity at any energy of interest directly using only information related to the superthreshold neutron flux as a function of energy and time. For example, to compute the neutron intensity at $100 \mathrm{eV}$, it 18 only necessary to store the flux dependence above $570 \mathrm{keV}$; one need not compute the flux at $200 \mathrm{eV}$.

The probiem of slowing down in lead is quite analogous to the deep-penetration problem in shieldIng. In the latter case, one is concerned primar11y with the few neutrons that are able to traverse many mean free paths. These neutrons typically get "free rides" through windows in the total cross 
section, so it is Important to consider these cross section features carefully. Slowing down in lead is a deep-penetration problem in the energy varlable Instead of the spatial variable. Neutrons generaily undergo many collistons and leak from the system before being degraded appreciably in energy. Only those neutrons that recelve a "free ride" by $(n, 2 n)$ or discrete-inelastic interactions manage to slow down to lower energles before escaping from the system. Hence, it is important to consider these reactions carefully. Orders of magnitude discrepancles have been otserved in the extreme case of totally neglecting level interactions.

\section{COMPARISON OF SLAHM WITH KNOWN ANALYTIC AND} EXPERIMENTAL RESULTS

The numcrical results obtained from SLAHM in the simple case of energy-dependent elastlc scatterIng plus a single level of discrete inelastic scattering have bcan compared and agree well with the known analytic solution. In addition, Bergman's experimental work reported at the 1955 Geneva Conference has been modeled. He reports a counting rate of $250 \mathrm{cpm}$ for $100-\mathrm{eV}$ neutrons at the center of a 2-m lead pile. A count rate of $303 \mathrm{cpm}$ was computed using SLAHM. Thus, with reasonable confidence* in the ability to compute and understand the slowing down processes, one next considers some of the practical applications such as the ability to determine quantitatively the amount of ${ }^{239} \mathrm{Pu}$ and ${ }^{235} \mathrm{U}$ contained In mixed-oxide reactor fuel pins.

XI . . APPLICATION OF THE IEAD SLOWING-DOWN-TIME SPECTROMETER (LSDTS) TECHNIQUES TO SAFEGUARDS PROBLEMS

To differentlate between ${ }^{239} \mathrm{Pu}$ and ${ }^{235} \mathrm{U}$ using the LSDTS technique, Irradiations in at least two energy intervals are required in order to obtain two equations for two unknowns.

A review of the barn book ${ }^{9}$ suggests one region that may be applicable; this ts the region from 1.5 to $6.5 \mathrm{eV}$ shown in FIg. 1. The data for Fig. 1 were taken from the $1968 \mathrm{KFK}-750$ report. ${ }^{10}$ One 18 bound on the left by the well-known ${ }^{240} \mathrm{Pu}$ resonance at $1 \mathrm{eV}$, and on the right by the $6.67-\mathrm{eV}^{23{ }^{3}} \mathrm{U}$ resonance and the $7.8 \mathrm{eV}$ resonance of ${ }^{239} \mathrm{Pu}$. However, within the 2- to $6-\mathrm{eV}$ region, the cross sections limited, and more work must be done In this area.

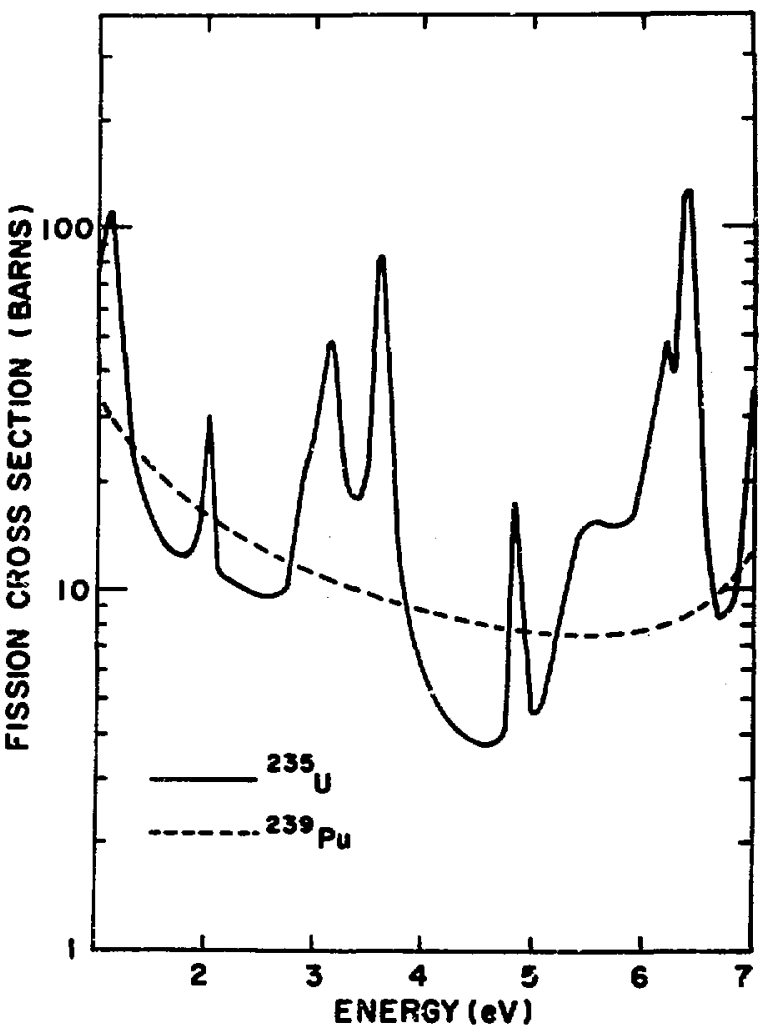

Fig. 1. $235 \mathrm{U}$ and ${ }^{239} \mathrm{Pu}$ fiselon cross sections, 1- to 7-eV energy.

are small enough not to present any self-shtelding problems of practical importance. If the count rate Is sufficlent, this appears to be an interesting possibility.

With respect to count-rate considerations, note Table II which fllustrates the sensftivity of the neutron intensity per unft volume to the dimensions of the pile. A substantial increase in intensity can be achleved by golng to larger cubes, particularly when considering lower energies (eV region). The dilution of the neutrons in the larger volume 18 more than compensated for by the reduced leakage. Lead cubes of about two meters on a side should be sufficlent to measure the prompt-fission neutrons induced in the $1.5-$ to $6.5-\mathrm{eV}$ region and provide meaningful statistics.

TABLE II

SENSITIVITZ OF NEUTRON INTENSITY PER VOLURE TO LIAD PILE DIMENSIONS

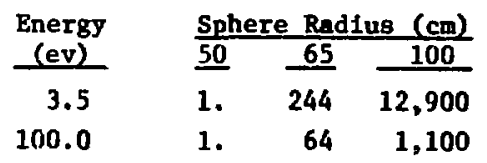


The 2.8- to 3.8-eV energy region iy deptcted In F1g. 2. It is characterized by an $230-\mu$ sec time Interval and ylelds a ${ }^{235} \mathrm{U} /{ }^{239} \mathrm{Pu}$ discrimination rat1o of $\sim_{2.5}$ without any Interfering resonance from $2{ }^{3} \mathrm{U}$ or higher isotopes of plutontum.

A second energy region of interest 18 that from 56 to $100 \mathrm{eV}$ shown $1 \mathrm{n} \mathrm{F1g.} \mathrm{3.} \mathrm{Data} \mathrm{for} \mathrm{this} \mathrm{figure}$ were taken from Lemley's recent measurements. 11

Earller German work by Baumung et al.12 examlned the region from 60 to $120 \mathrm{eV}$. We recommend here that the additional 2 usec corresponding to 56 to $66 \mathrm{eV}$ be Included because the plutonlum cross section is higher than the ${ }^{235} \mathrm{U}$ cross section by about a factor of three and the fissions induced will be a significant part ( $14 \%$ ) of the total. Conversely, the range from 100 to $120 \mathrm{eV}$, where the ${ }^{239} \mathrm{Pu} /{ }^{235} \mathrm{U}$ diacrimination capability is appreclably lower, was not includer. Note that crosa sections in the 56- to 100eV reglon are substantially higher, and self-shleldIng corrections up to $\sim 30 \%$ could be introduced, depending upon the fiel composition. If the plutonium concentration is known, a priorl, to be that high, a more satisfactory approach is indicated In Fig. 4 which suggests that one focus attention on the nore restricted 56- to $66^{-} \mathrm{eV}$ range. This is a more difficult experiment because the counting time involved is $\sim 3$ to $4 \mu \mathrm{sec}$ so the source pulse width must be confined to less than 1 usec. However, such an approach effectiveig eliminates the self-shlelding

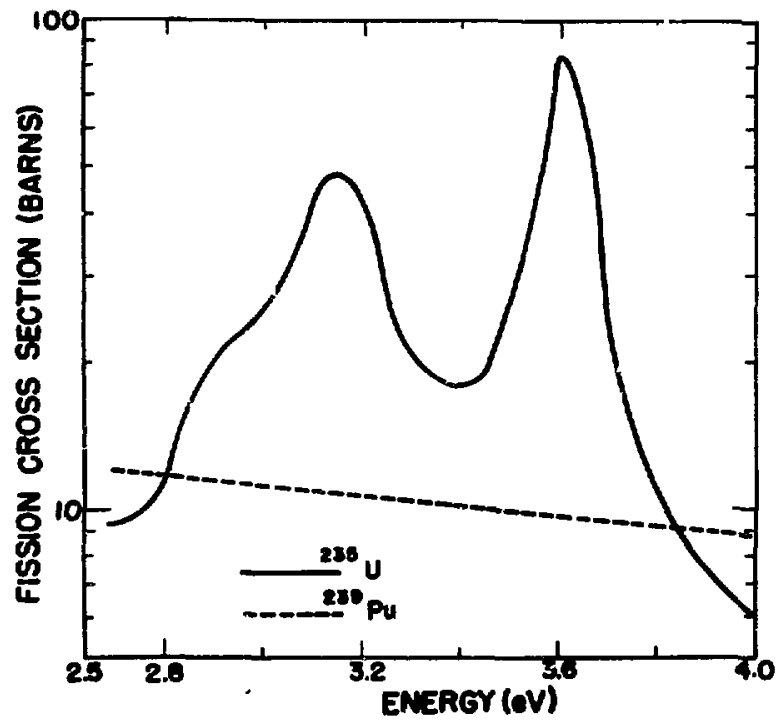

F1g. 2. ${ }^{235} \mathrm{U}$ and ${ }^{239} \mathrm{Pu}$ fiasion cross sectlons, 2.8- to 3.8-eV energy.

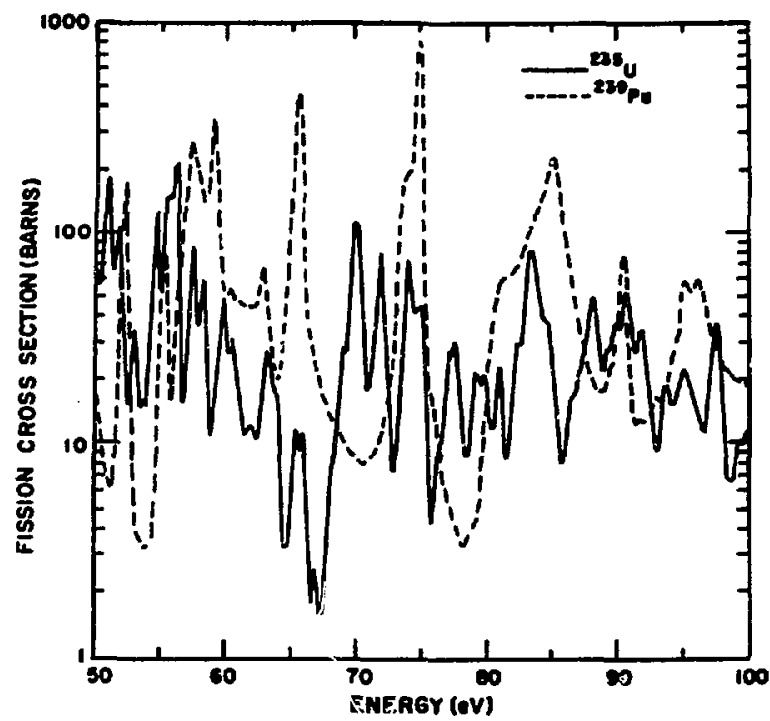

Fig. 3. ${ }^{235} \mathrm{U}$ and ${ }^{239} \mathrm{Pu}$ fission cross sections 56- to $100-\mathrm{eV}$ energy.

problems by entirely avolding the 75-eV resonance of ${ }^{299} \mathrm{Pu}$; the count-rate $108 s$ due to diminished source Intensity and counting time 18 more than compensated by the factor of ten increase in ${ }^{239} \mathrm{Pu}$ concentration in fast-reactor fuels.

To sim up, we propose application of the LSDTS techntque using a $2-\mathrm{m}^{3}$ lead pile with investigation of the 2.8- to 3.8- and 56- to 100-eV energy ranges, or for fast-breeder, high-plutonfum-concentration plns, the 2.8- to 3.8- and 56- to 66-eV rrnges.

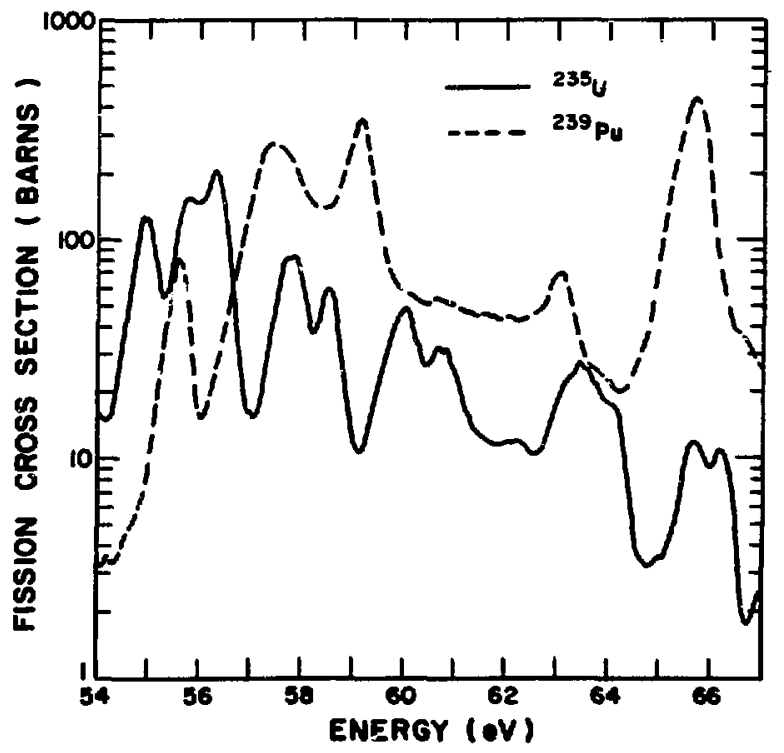

P1g. 4. ${ }^{295} \mathrm{U}$ and ${ }^{239} \mathrm{Pu}$ fission cross sections, 54- to 67-ey energy. 
The net discrimination

$$
\begin{aligned}
D= & \left(\frac{\text { counts }{ }^{235} \mathrm{U}}{\text { counts }{ }^{239} \mathrm{Pu}}\right) \\
& \times\left(\frac{\text { counts }{ }^{239} \mathrm{Pu}}{\text { counts }^{235} \mathrm{U}}\right)_{56 \text { to }} 100 \mathrm{eV}
\end{aligned}
$$

achleved in approximately five. Table III presents estimates of counting rates for these regions uaing the results obtained from SLAHM. These counting rates were cbtained assuming, a $2 \times 10^{8} \mathrm{n} / \mathrm{sec}$ source of 14-MeV neutrons, 1-m- long fuel pins, wl cm in diameter, and $0.2 \%$ detector efficlency.

\section{TABLE III}

EXPECTED COUNT FATE IN A 2-m-DIAM LEAD SPHERE AS A FUNCTION OF FUEL CONPOSITIONa

\begin{tabular}{|c|c|c|c|}
\hline \multicolumn{2}{|c|}{$\begin{array}{l}\text { Composition } \\
\text { (\%) }\end{array}$} & $\begin{array}{c}(56 \text { to } 100 \mathrm{eV}) \\
(\mathrm{cpm})\end{array}$ & $(2.8$ to $3.8 \mathrm{eV})$ \\
\hline $\begin{array}{l}235 \mathrm{U} \\
2{ }^{39} \mathrm{Pu}\end{array}$ & $\begin{array}{l}2.5 \\
0.5\end{array}$ & 1,500 & 540 \\
\hline $\begin{array}{l}235 \mathrm{U} \\
{ }^{239} \mathrm{Pu}\end{array}$ & $\left.\begin{array}{r}0.5 \\
20.0\end{array}\right\}$ & 23,000 & 1,300 \\
\hline $\begin{array}{l}235 \mathrm{U} \\
23{ }^{29} \mathrm{Pu}\end{array}$ & $\begin{array}{l}8.0 \\
8.0\end{array}$ & $12,00 \mathrm{C}$ & 2,200 \\
\hline
\end{tabular}

Fuel Average Count Rate Average Count Rete

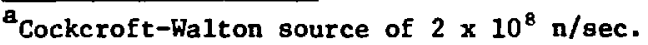

\section{CONCLUSIONS}

1. There are two natural energy ranges (2.8 to 3.8 and 56 to $100 \mathrm{eV}$ ) that together provide a discrimination factor of 5 between ${ }^{239} \mathrm{Pu}$ and ${ }^{295} \mathrm{U}$ with little problem of self-shtelding induced by these two isotopes.

2. For typical fast-breeder fuel compositions, the application of the LSDTS technique using a 2-mdiam lead sphere Involves assay times of $<10$ min for $1 \%$ counting statistics.

3. Our analysis of the slowing down process has provided a technfque by which to compute the appropriate subthreshold (for tnelastic processes) source for neutron slowing down in lead.

4. The effective age of $14-\mathrm{MeV}$ neutrons in lead has been shown to be very sensitive to the "effective" Inttlal spectrum as shown in Table $I$.
REFERENCES

1. A. A. Bergman, A. I. Isakov, I. D. Gurin, F. L. Shap1ro, I. V. Shtrantkh, and M. V. Kezernovek1, "A Neutron Spectrometer Based on Measuring the Slowing-Down Time of Neutrons in Lead," Pros. Intern. Conf. Peaceful Uses At. Energy, Geneva, 1955, P/642, Vol. IV, PP. 135-146 (1955).

2. H. Krinninger, S. Hesner, and $C_{\text {. }}$ Faber, "Pulsed Neutron Method for Nondestructive and Simultaneous Determination of the ${ }^{235} \mathrm{~V}$ and ${ }^{29} \mathrm{Pu}$ Contents of Irradiated and Non-Irradiated Reactor Fuel Elements," Nucl. Instr. Meth., 73 13 (1969).

3. D. Stegamann and H. Seufert, "AppIlcation of the Slowing Down Time Spectrometer for the Control of Flssionable Materlal," Trans. A. Nucl. Soc., 11, 658 (1968).

4. M. P. Navalkar, K. Chandramoleshwar, and D. V. S. Ramakrishna, "A Feasibility Study of Hondestructive Assay of ${ }^{23{ }^{3}} \mathrm{Pu}$ and ${ }^{235} \mathrm{O}$ in Irrad $1-$ ated Samples Dsing a Slowing Down Lead Spectrometer," Nukleonlk, 11, 54 (1968).

5. R. L. Bramblett, R. O. GInaven, T. Gozani, A. T. Hyde, L. A. Ku11, J. I. Hckillan, D. B. Rundquist, and G. D. Trimble, "Application of Photolnduced Reactions to Nuclear Materials Safeguards Problems," GA-10272, pp. 77-85, Gulf Radiation Technology (1970).

6. T. J. Williamson and R. W. Albrecht, "Calculations of Neutron Time-Energy Distributions in Heavy Moderator8," Nuc1. Sc1. Eng., 42, 97 (1970).

7. J. R. Beyster, "The Application of the Slowing Down Spectrometer to Nuclear Materials Assay," BNL-50232, Brookhaven National Laboratory (1970).

8. B. R. S. Buckingham, R. Parker, and E. D. Pendlebury, "Neutron Cross Sections of Selected Elements and Isotopes for Use In Neutronic Celculations in the Energy Range .025 ev-15 MeV," AGRE-0-28/60, Atomlc Weapons Research Bstablishment, Aldermaston, Bngland (1961).

9. John R. Stehn, Murrey D. Goldberg, Renate Wiener-Chasman, Sald F. Mughabghab, Benjanin A. Magurno, and Victoria M. May, "Neutron Cross Sections," BNL-325, Vo1. III, Brookhaven Naticnal Laboratory (1965).

10. I. Langner, J. J. Schmidt, and D. Woll, "Tablea of Evalusted Neutron Cross Sections for Fast Reactor Materials," RFK 750, Inst1tute Für Neutronenphysik und Reaktortechnik, Karlsruhe, Germany (1968).

11. J. R. Lemley, G. A. Keyworth, and B. C. Diven, "High Resolution Fission Cross Section of Dranium-235 from $20 \mathrm{eV}$ to $100 \mathrm{keV}$," Nucl. Scl. Eng., 43, (1971).

12. R. Baumung, R. Böhnel, J. Klunksr, M. Küchle, and $J$. Wolff, "Investigations Into Non-Destructive Sefeguards Techniques," in Sefeguards Techntques, Proceedings of a Symposium in Karlsruhe, July 6-10, 1970, IAEA-SM-133/90, vol. II, pp. 177-192. 